\title{
KOMPARASI PENDAPATAN USAHATANI PADI DENGAN SAYURAN PADA MUSIM TANAM II DI LAHAN SAWAH IRIGASI DESA SUMEDANG SARI BUAY MADANG TIMUR
}

(Aisah)

\begin{abstract}
The purpose of this research is to: (1) To find out what underlies irrigated paddy farmers to grow vegetables during planting season II (technically and financially) in Sumedang Sari Village, East Buay Madang District, OKU Timur Regency, (2) Rice and vegetable farming in Sumedang Sari Village, Buay Madang Timur District. Determination of location is done purposively (Purposive) with the reason in Sumedang Sari Village is one of the villages that have rice farming and some of them are farming in irrigated rice field. This study was conducted from May to June 2013. The study found that farmers' perceptions of their farming (rice and vegetables) and the positive impact of the farming on paddy fields. From the perception of farmers perception of rice obtained an average score of 14.20 and 56.80\% percentage that entered on neutral criteria. As for the perception of vegetable farmers obtained an average score of 17.50 and $70.00 \%$ percentage that entered on the criteria agreed, which means that vegetable farming has a positive impact on the fertility of paddy fields. And from result of analysis of rice farming obtained $R / C$ ratio equal to 1,50, while result of analysis of vegetable farming obtained $R / C$ ratio equal to 3,05. From the analysis of perception and $R / C$ value, the ratio of vegetable farming is superior to rice farming. Revenue of paddy farming is Rp. 5,032,800 LG / MT or Rp. 1.258.200 LG / Bln or Rp. 6,150,926 Ha / Month and the cost of Rp. 3.375.199,17 LG / MT or Rp. 843.799,79 LG / Bln or Rp. 4.107.326,43 Ha / Bln, then the income of rice farming is Rp. 1.657.600,83 LG / MT or Rp. 414.400,21 LG / Bln or Rp. 2,043,599,50 $\mathrm{Ha} / \mathrm{Bln}$. As for the acceptance of vegetable farming Rp. 17.569.500 LG / MT or Rp. 3.817.984,09 LG / Bln or Rp. 18,392,939.77 Ha / Month and the cost of Rp. 5.856.209,67 LG / MT or Rp. 1.261.602,66 LG / Bln or Rp. 6,087,723.43 Ha / month, then the income of vegetable farming income is Rp. 11.713.290,33 LG / MT or Rp. 2.556.381,43 LG / Bln or Rp. 12.305.216,38 Ha / Bln. From the average income income, vegetable farming income is higher than the income of rice farming. While the resulting income difference of Rp. 10,055,689,5 LG / MT or Rp. 2.141.981,22 LG / Bln or Rp. 10,261,616.88 Ha / Bln.
\end{abstract}

Key Words : Agricultural Science, Revenue Comparison, Rice plants, and Vegetable Crops.

\section{PENDAHULUAN}

\section{A. Latar Belakang}

Pembangunan pertanian berkelanjutan merupakan strategi pembangunan jangka panjang bertujuan untuk mewujudkan pertanian agar lebih maju, efektif, efisien yaitu pertanian yang peka terhadap arti pentingnya lingkungan hidup teknologi dan inovasi baru. Pertanian kompetitif dan mandiri dapat memperdayakan ekonomi petani dalam memenuhi kebutuhan pangan dan komoditas lainnya. Dalam usaha peningkatan produksi pangan tidak hanya terbatas pada padi dan palawija saja, sektor hortikultura (sayuran dan buah-buahan) mempunyai potensi yang cukup tinggi untuk dikembangkan (Sunarjono, 2005).

Salah satu bagian pembangunan pertanian yang mempunyai kedudukan sangat strategis adalah kegiatan yang berbasis pada tanaman pangan dan hortikultura. Sektor ini selain melibatkan tenaga kerja terbesar dalam kegiatan produksi, produknya merupakan bahan pangan pokok pada konsumsi pangan nasional. Dengan kedudukan ini produk tanaman pangan dan hortikultura menjadi faktor utama dalam menentukan biaya hidup di Indonesia. Dilihat dari sisi bisnis kegiatan ekonomi yang berbasis pangan dan hortikultura merupakan kegiatan bisnis terbesar dan tersebar luas di seluruh Indonesia (Anonim, 2011).

Untuk meningkatkan hasil produksi pertanian tanaman pangan harus terus di upayakan, salah satu upaya yang dilakukan adalah menganekaragamkan komoditi dalam berusahatani, jangan terus menerus berusahatani yang sama dari musim ke musim, perlu adanya pergantian komoditi dalam tiap musimnya serta memanfaatkan lahan kosong (Anonim, 2011).

Padi merupakan tanaman pangan yang berbentuk biji-bijian yang menghasilkan beras. Padi menjadi bahan makanan pokok untuk memenuhi kesejahteraan penduduk Indonesia. Pertumbuhan dan produksi padi dapat dipengaruhi oleh faktor-faktor lingkungan, yang dibagi dalam dua golongan yaitu:

a.Faktor lingkungan alamiah seperti tanah, iklim, dan biologis. 
b. Faktor sarana produksi seperti pupuk, obatobatan, pemberantasan hama dan penyakit, varietas padi unggul yang diberikan manusia (Anonim, 2011).

Produksi padi sangat tergantung pada musim yang dapat mempengaruhi kegiatan produksi. Sifat curah hujan yang sangat bervariasi mempunyai pengaruh yang besar pada produksi pertanian. Variasi curah hujan tahunan terutama menyebabkan kegagalan tanam atau panen akibat kekeringan atau banjir. Meskipun secara umum awal musim hujan telah diketahui, namun sifat curah hujan selama musim tanam masih sulit diprediksi karena sangat bervariasi dari tahun ke tahun. Padi adalah tanaman yang membutuhkan air untuk pertumbuhannya (Anonim, 2011).

Selain padi, sayuran juga mempunyai peluang bisnis yang strategis seperti tanaman kacang panjang, mentimun, pare dan terong. Sayuran selain menjadi konsumsi pokok dalam negeri juga mempunyai peluang ekspor baik dalam bentuk olahan maupun segar. Budidaya kacang panjang, mentimun, pare dan terong dapat dikembangkan di seluruh Indonesia baik di dataran rendah sampai ke wilayah pegunungan, sayangnya produktivitas secara nasional masih tergolong rendah (Setiadi, 2007).

Tingkat produktivitas yang rendah disebabkan faktor-faktor produksi yang belum efisien dan penguasaan teknologi budidaya oleh petani masih rendah. Dimana rata-rata petani hanya mengandalkan populasi tanaman yang tinggi tanpa diimbangi dengan penerapan teknologi yang intensif. Maka perlu adanya penguasaan teknik budidaya oleh petani agar jumlah kombinasi faktor-faktor produksi yang digunakan optimal, sehingga syarat-syarat efisiensi produk dapat tercapai.

Keberhasilan suatu usahatani tentunya dipengaruhi oleh faktor intern dan ekstern. Faktor intern adalah faktor produksi fisik yang digunakan dalam usahatani seperti benih, pupuk, lahan, tenaga kerja yang secara langsung mempengaruhi produktivitas tanaman. Faktor ekstern adalah faktor diluar usahatani yang berpengaruh terhadap keberhasilan usahatani tetapi tidak berpengaruh langsung terhadap produktivitas tanaman seperti transportasi, fasilitas kredit dan yang terpenting adalah pemasaran (Hernanto, 2005).

Provinsi Sumatera Selatan khususnya Kabupaten OKU Timur merupakan kabupaten yang memiliki potensi sebagai lumbung pangan. Sektor pertanian akan menjadi tumpuan pembangunan ekonomi dengan meningkatkan kualitas dan berorientasi pada usahatani untuk dapat mencukupi kebutuhan menjadi pendekatan agribisnis untuk mencapai kesejahteraan wilayah pedesaan. Dengan ketersediaan modal usaha yang memadai, sarana produksi yang cukup serta didukung oleh sumber daya manusia yang handal diyakini akan menjadi usaha agribisnis menjadi daya saing (Anonim, 2010).

Kabupaten OKU Timur merupakan kabupaten yang memiliki potensi yang cukup baik dibidang pertanian. Lahan pertanian yang mendukung untuk berusaha tani padi memicu sebagian petani untuk menganekaragamkan komoditi selain padi sawah (sayuran) yang bertujuan untuk meningkatkan produktivitas hasil pertanian (Anonim, 2010).

Desa Sumedang Sari terletak di Kecamatan Buay Madang Timur dengan luas lahan pertanian \pm 70 Ha merupakan salah satu desa penghasil padi, selain itu ada sebagian petani yang berusahatani sayuran.

\section{B. Rumusan Masalah}

1. Apa yang mendasari petani lahan sawah irigasi menanam sayuran pada musim tanam II di Desa Sumedang Sari Kecamatan Buay Madang Timur Kabupaten OKU Timur di lihat dari sisi kelayakan teknis dan finansial.

2. Berapa besar perbedaan pendapatan lahan sawah irigasi pada musim tanam II antara komoditi padi dengan sayuran di Desa Sumedang Sari Kecamatan Buay Madang Timur Kabupaten OKU Timur.

\section{Tujuan dan Kegunaan}

1. Untuk mengetahui apa yang mendasari petani lahan sawah irigasi menanam sayuran pada musim tanam II (secara teknis dan finansial) di Desa Sumedang Sari Kecamatan Buay Madang Timur Kabupaten OKU Timur.

2. Untuk mengetahui perbandingan pendapatan usahatani padi dan sayuran di Desa Sumedang Sari Kecamatan Buay Madang Timur Kabupaten OKU Timur. 


\section{Model Pendekatan}

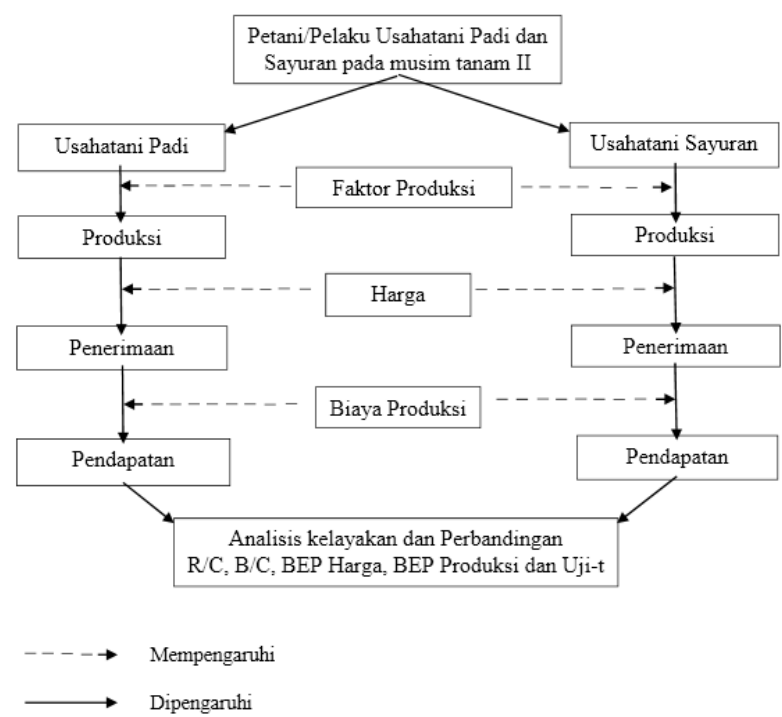

Gambar 1. Model pendekatan penelitian secara diagramatik

\section{METODOLOGI PENELITIAN}

\section{A. Tempat dan Waktu}

Penelitian ini telah dilaksanakan di Desa Sumedang Sari Kecamatan Buay Madang Timur. Penentuan lokasi dilakukan secara sengaja (Purposive) dengan alasan di Desa Sumedang Sari adalah salah satu Desa yang berusahatani padi dan sebagian ada yang berusahatani sayuran dilahan sawah irigasi. Penelitian ini telah dilaksanakan pada bulan Mei sampai dengan Juni 2013.

\section{B. Metode Penelitian}

Metode penelitian yang digunakan dalam penelitian ini adalah metode survei (survey study). Pengertian survei dibatasi pada pengertian survei sampel dimana informasi dikumpulkan dari beberapa petani untuk mewakili seluruh populasi. Dalam penelitian survei informasi dikumpulkan dari responden dengan menggunakan quisioner sebagai alat pengumpul data yang pokok.

\section{Metode Penarikan Contoh}

Metode penarikan contoh yang digunakan dalam penelitian ini adalah purposive (sengaja) dimana dari jumlah populasi 169 petani padi, terdapat 10 petani yang berusahatani sayuran, kemudian untuk membandingkan pendapatan usahatani sayuran dengan padi maka petani padi dipilih sesuai dengan kriteria dan luas lahan garapan yang sama, dari hasil survai ditemukan 10 petani padi yang memiliki kriteria dan luas garapan yang sama.

\section{Metode Pengolahan Data}

Data yang telah diperoleh dari lapangan dikelompokkan diolah secara tabulasi. Untuk menjawab hipotesis nomer satu yaitu dengan menggunakan Skala Likert. Menurut Sugiyono (2012), Skala Likert digunakan untuk mengukur sikap, dan persepsi seseorang atau kelompok orang tentang fenomena. Jawaban setiap item instrument yang menggunakan skala likert mempunyai gradasi dari sangat positif hingga negatif. Data dari pertanyaan dengan skala likert tersebut kemudian dianalisa berdasarkan skor setiap jawaban dari responden (tingkat persetujuan), maka digunakan rumus:

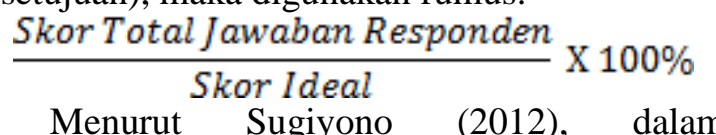
menanggapi pertanyaan dalam skala likert, responden menentukan tingkat persetujuan mereka terhadap suatu pernyataan dengan memilih salah satu dari pilihan yang tersedia. Ada dua bentuk pertanyaan yang menggunakan likert yaitu pertanyaan positif untuk mengukur minat positif, dan bentuk pertanyaan negatif untuk mengukur minat negatif.

Tabel 1. Biasanya disediakan lima pilihan skala dengan format seperti :

\begin{tabular}{llc}
\hline No & Pendapat & Skor Positif \\
\hline 1. & Sangat tidak setuju & 1 \\
2. & Tidak setuju & 2 \\
3. & Netral & 3 \\
4. & Setuju & 4 \\
5. & Sangat setuju & 5 \\
\hline
\end{tabular}

Sumber : Sugiyono, 2012.

Setelah melakukan perhitungan menggunakan Skala Likert maka selanjutnya dihitung menggunakan Uji Validitas. Uji validitas dilakukan untuk mengetahui sampai sejauh mana ketepatan dan ketelitian antara hasil pengukuran dari variabel yang diteliti dengan teori. Hasil penelitian dikatakan valid apabila terdapat kesamaan antara data yang terkumpul dengan data yang sesungguhnya terjadi pada objek yang diteliti.

Menurut Husein Umar (2002) untuk pengujian tingkat validitas instrumen dalam penelitian digunakan teknik analisis Koefisien Korelasi Produk-Moment Pearson (Pearson Product-Moment Corelation Coeficient) dengan rumus sebagai berikut :

$$
r_{x y}=\frac{n \sum X Y-\sum X \sum Y}{\sqrt{\left(n \sum X^{2}-\left(\sum X\right)^{2}\left(n \sum Y^{2}\right)-\left(\sum Y\right)^{2}\right)}}
$$

Dimana : 
$r_{x y}=$ Koefisien korelasi pearson antara item instrumen yang akan digunakan dengan variabel yang bersangkutan.

$\mathrm{X}=$ Skor instrumen yang akan digunakan.

$\mathrm{Y}=$ Skor semua item instrumen dalam variabel tersebut.

$\mathrm{n}=$ Jumlah instrumen sementara.

Kaidah :

r_hitung $\geq r_{\text {__tabel maka instrument mempunyai }}$ validitas yang tinggi.

r_hitung < r_tabel maka instrument tersebut dinyatakan tidak valid.

Guna menjawab lanjutan hipotesis ke 1 dan hipotesis ke 2 untuk menghitung kelayakan dan perbandingan maka harus menghitung dulu jumlah biaya produksi, penerimaan dan pendapatan digunakan rumus sebagai berikut:

1. Untuk mengetahui biaya produksi menggunakan rumus (Suratiyah, 2006):

$\mathrm{BP}=\mathrm{BT}+\mathrm{BV}$

$\mathrm{BP}=$ Biaya Produksi (TC / Total Cost $)$

$\mathrm{BT}=$ Biaya Tetap (FC / Fixed Cost)

$\mathrm{BV}=$ Biaya Variabel (VC / Variabel Cost)

2. Untuk mengetahui penerimaan menggunakan rumus (Suratiyah, 2006):

$\mathrm{R}=\mathrm{P} \times \mathrm{Y}$

$\mathrm{R}=$ Penerimaan (Revenue)

$\mathrm{P}=$ Harga

$\mathrm{Y}=$ Produksi (yang diperoleh dalam usahatani padi dan sayuran) (Yield)

3. Untuk mengetahui pendapatan menggunakan rumus (Suratiyah, 2006):

$\mathrm{B}=\mathrm{R}-\mathrm{BP}$

$\mathrm{B}=$ Benefit (Pendapatan / Income $)$

$\mathrm{R}=$ Penerimaan (Revenue)

$\mathrm{BP}=$ Biaya Produksi (TC / Total Cost $)$

4. Revenues Cost Ratio (R/C Ratio)

Revenues Cost Ratio adalah analisis kelayakan usaha dengan perbandingan penerimaan kotor dengan biaya total yang dikeluarkan secara matematis dirumuskan:

$$
\mathrm{R} / \mathrm{C}=\frac{\mathrm{R}}{\mathrm{TC}}
$$

Keterangan:

$\mathrm{R}=$ Revenues (Penerimaan)

$\mathrm{TC}=$ Total Cost $($ Total Biaya Produksi $)$

$\mathrm{R} / \mathrm{C}=$ Rasio atau perbandingan, dimana:

$\mathrm{R} / \mathrm{C}>1=$ usaha dinyatakan layak

$\mathrm{R} / \mathrm{C}<1=$ usaha dinyatakan tidak layak

$\mathrm{R} / \mathrm{C}=1=$ impas

5. Benefit Cost Ratio (B/C Ratio)

Benefit Cost Ratio adalah analisis kelayakan usaha dengan membandingkan meningkatnya pendapatan usahatani akibat bertambahnya biaya produksi karena perubahan penerapan teknologi:

$$
\mathrm{B} / \mathrm{C}=\frac{\mathrm{B}}{\mathrm{TC}}
$$

Keterangan:

$\mathrm{B}=$ Benefit (Pendapatan)

$\mathrm{TC}=$ Total Cost (Total Biaya Produksi)

$\mathrm{B} / \mathrm{C}=$ rasio atau perbandingan, dimana:

$\mathrm{B} / \mathrm{C} \geq 1=$ usaha dinyatakan layak

$\mathrm{B} / \mathrm{C} \leq 1=$ usaha dinyatakan tidak layak

6. Untuk mengetahui Break Event Point Harga menggunakan rumus (Suratiyah, 2006):

$$
\mathrm{BEP}=\frac{\mathrm{TC}}{\mathrm{Y}}
$$

Dimana:

BEP = Titik Impas Harga

$\mathrm{Y}=$ Jumlah Produksi (Yield)

$\mathrm{TC}=$ Total Biaya $(\mathrm{TC} /$ Total Cost $)$

Kriteria:

BEP harga $<$ harga jual = usaha dinyatakan layak

BEP harga > harga jual = usaha dinyatakan tidak layak.

$\mathrm{BEP}$ harga = harga jual = usaha dinyatakan impas

7. Untuk mengetahui Break Event Point Produksi menggunakan rumus (Suratiyah, 2006):

$$
\mathrm{BEP}=\frac{\mathrm{FC}}{\mathrm{P}-\mathrm{AVC}}
$$

Dimana:

BEP $=$ Titik Impas Produksi

$\mathrm{FC}=$ Biaya Tetap $(\mathrm{FC} /$ Fixed Cost $)$

$\mathrm{P}=$ Price (Harga Jual)

$\mathrm{AVC}=$ Biaya Variabel rata- rata $(\mathrm{AVC} /$ Average Variabel Cost)

Kriteria:

$\mathrm{BEP}$ produksi $<$ total produksi = usaha dinyatakan layak

BEP produksi > total produksi = usaha dinyatakan tidak layak

$\mathrm{BEP}$ produksi $=$ total produksi $=$ usaha dinyatakan impas

8. Untuk mengetahui perbandingan pendapatan padi dengan sayuran menggunakan rumus Uji-t (Sugiyono, 2012):

Sebelum menghitung Uji-t, terlebih dahulu harus menentukan rumus mana yang akan dipakai, dalam menghitung Uji-t ada beberapa rumus t-test yang digunakan. Dan berikut ini pedoman penggunaannya:

a) Bila jumlah anggota sampel $n_{1}=n_{2}$, dan varian homogen maka dapat digunakan rumus t-tes baik untuk separated, maupun pool varian. (Rumus 1 dan 2). Untuk melihat harga t-tabel digunakan $\mathrm{dk}=\mathrm{n}_{1}+\mathrm{n}_{2}-2$. 
b) Bila $\mathrm{n}_{1} \neq \mathrm{n}_{2}$, varian homogen, dapat digunakan rumus t-test dengan pooled varian. (Rumus 2). Derajat kebebasannya (dk) $=$ $\mathrm{n}_{1}+\mathrm{n}_{2}-2$.

c)Bila $n 1=n 2$, varian tidak homogen dapat digunakan rumus 1 dan 2 , dengan $\mathrm{dk} \mathrm{n}_{1}-1$ atau $\mathrm{n}_{2}-1$. Jadi dk bukan $\mathrm{n}_{1}+\mathrm{n}_{2}-2$.

d) Bila $\mathrm{n}_{1} \neq \mathrm{n}_{2}$ dan varian tidak homogen, untuk ini digunakan t-test dengan separated varian, rumus 1 harga $t$ sebagai pengganti ttabel dihitung dari selisih harga t-tabel dengan $\mathrm{dk}\left(\mathrm{n}_{1}-1\right)$ dan $\mathrm{dk}\left(\mathrm{n}_{2}-1\right)$ dibagi dua, dan kemudian ditambahkan dengan harga $t$ yang terkecil.

e)Bila sampel berkorelasi atau berpasangan, misalnya membandingkan sebelum dan sesudah treatment atau perlakuan, atau membandingkan kelompok kontrol dengan kelompok eksperimen, maka digunakan t-test sampel related. Rumus 3, yaitu ;

Rumus-rumus t-tes:

1) $\mathrm{t}=\frac{\overline{\mathrm{X}}_{1}-\overline{\mathrm{X}}_{2}}{\sqrt{\frac{S_{1}^{2}}{n_{1}}+\frac{S_{2}^{2}}{n_{2}}}}$

2) $\mathrm{t}=\frac{\overline{\mathrm{X}}_{1}-\overline{\mathrm{X}}_{\mathrm{z}}}{\sqrt{\frac{\left(n_{1}-1\right) \mathrm{s}_{1}^{\mathrm{n}}+\left(n_{2}-1\right) \mathrm{s}_{2}^{\mathrm{n}}}{n_{1}+n_{2}-2}\left(\frac{1}{n_{1}}+\frac{1}{n_{2}}\right)}}$

3) $\mathrm{t}=\frac{\overline{\mathrm{x}}_{1}-\overline{\mathrm{x}}_{2}}{\sqrt{\frac{s_{1}^{2}}{n_{1}}+\frac{s_{2}^{2}}{n_{2}}-2 r\left(\frac{s_{1}}{\sqrt{n_{1}}}\right)\left(\frac{s_{2}}{\sqrt{n_{2}}}\right)}}$

$\overline{\mathrm{X}}_{1}=$ rata-rata pendapatan petani padi

$\overline{\mathrm{X}}_{2}=$ rata-rata pendapatan petani sayuran

$\mathrm{n}_{1}=$ sampel petani padi

$\mathrm{n}_{2}=$ sampel petani sayuran

$\mathrm{s}_{1}^{2}=$ varian sampel padi

$\mathrm{s}_{2}{ }^{2}=$ varian sampel sayur

$\mathrm{r}=$ korelasi antara dua sampel

Sedangkan untuk mengetahui dua varian sampel tersebut homogen atau tidak, maka perlu diuji homogenitas variannya terlebih dahulu dengan uji $\mathrm{F}$.

$$
\begin{aligned}
& \mathrm{F}=\frac{\text { Varian terbesar }}{\text { Varian terkecil }} \\
& \mathrm{F}=\frac{7.925 .715 .721 .572}{94.859 .374 .773}=83,55
\end{aligned}
$$

Hasilnya selanjutnya dibandingkan dengan harga $F$ tabel dengan $\mathrm{dk}$ pembilang $(10-1=9)$ dan dk penyebut $(10-1=9)$. Berdasarkan dk tersebut dan untuk kesalahan $5 \%$, maka harga $\mathrm{F}$ tabel $=3,18$. Ternyata harga $F$ hitung lebih besar dari $F$ tabel $(83,55>$ 3,18 ). Dengan demikian dapat dinyatakan bahwa varian ke dua kelompok data tersebut adalah tidak homogen.

\section{HASIL DAN PEMBAHASAN}

\section{A. Analisis Persepsi Petani terhadap Usahatani Padi dan Sayuran.}

Untuk mencari bagaimana persepsi petani padi dan petani sayuran terhadap usahataninya tersebut diperlukan cara untuk mengetahui persepsi petani tersebut yaitu dengan menggunakan skala likert. Skala likert disini digunakan untuk mengukur persepsi petani terhadap kejadian yang ada pada lingkungannya. Menurut Sugiyono (2012), dalam menanggapi pertanyaan dalam skala Likert, responden menentukan tingkat persetujuan mereka terhadap suatu pernyataan dengan memilih salah satu dari pilihan yang tersedia (tabel 1).

Setelah membuat skor persepsi petani padi dan petani sayuran selanjutnya mencari nilai interval (jarak) dengan membuat persentase pada setiap skor pada persepsi tersebut dengan rumus interval yaitu :

$$
I=\frac{100 \%}{\text { Tumlah Skor }}
$$

Keterangan :

$$
\begin{aligned}
& \text { I }=\text { Interval } \\
& \text { Jumlah skor }=5
\end{aligned}
$$

Maka hasil interval diatas adalah 20\%, sehingga interval dari terendah yaitu $0 \%$ hingga $100 \%$ adalah dengan kategori sebagai berikut:

1. Persentase $0 \%$ hingga $19,99 \%$ adalah sangat tidak setuju

2. Persentase $20 \%$ hingga $39,99 \%$ adalah tidak setuju

3. Persentase $40 \%$ hingga $59,99 \%$ adalah netral

4. Persentase $60 \%$ hingga $79,99 \%$ adalah setuju

5. Persentase $80 \%$ hingga $100 \%$ adalah sanga setuju

Tabel 2. Persepsi petani padi dan sayuran di Desa Sumedang Sari Kecamatan Buay Madang Timur Kabuaten OKU Timur.

\begin{tabular}{lcc} 
& Madang & Petani Sayuran \\
\hline Uraian & 142 & 175 \\
\hline Total skor & 14,20 & 17,50 \\
Rata-rata & 5 & 5 \\
skor tinggi & 56,80 & 70,00 \\
Persentase & Netral & Setuju
\end{tabular}

Sumber: Data olahan Primer, 2013.

Dari persepsi petani diatas, skor total petani padi adalah 142 dengan rata-rata skor total sebesar 14,20 dan persentase sebesar 56,80 \%, maka persentase petani padi masuk pada kriteria netral. Sedangkan skor total petani sayuran yang 
diperoleh sebesar 175 dengan rata-rata skor sebesar 17,50 dan persentase sebesar 70,00\%, maka persentase petani sayuran masuk pada kriteria setuju.

Kemudian dilanjutkan menggunakan rumus korelasi, sebagai berikut:

$$
r_{x y}=\frac{n \sum X Y-\sum X \sum Y}{\sqrt{\left(n \sum X^{2}-\left(\sum X\right)^{2}\left(n \sum Y^{2}\right)-\left(\sum Y\right)^{2}\right)}}
$$

Korelasi Usahatani Padi

$$
r_{x y}=\frac{69}{\sqrt{(202)(96)}}=0,689
$$

Korelasi Usahatani Sayuran

$$
r_{x y}=\frac{345}{\sqrt{(257)(345)}}=1,159
$$

Dari hasil perhitungan menggunakan rumus korelasi, untuk usahatani padi diperoleh r_hitung sebesar 0,689 dan untuk usahatani sayuran diperoleh r_hitung sebesar 1,159. Sedangkan r_tabel yang dihasilkan sebesar 0,632. Jadi hasil korelasi usahatani padi dan sayuran dikatakan signifikan dengan selisih 0,47 usahatani sayuran lebih unggul dibandingkan usahatani padi.

\section{B. Analisis Biaya, Produksi, Penerimaan, Pendapatan, R/C, B/C, BEP Harga dan BEP Produksi Usahatani Padi dan Sayuran.}

Analisis biaya dilakukan sebagai tolak ukur suatu usaha apakah menguntungkan atau tidak dan apakah usaha tersebut layak untuk dikembangkan atau tidak. Untuk menganalisa usaha adalah dengan menghitung besarnya biaya produksi yang dikeluarkan, produksi padi dan sayuran yang dihasilkan, penerimaan dan pendapatan yang diperoleh oleh responden. Dalam penelitian biaya yang digunakan adalah biaya per proses produksi selama masa tanam.

\section{Biaya Produksi Usahatani Padi dan Sayuran}

Total biaya adalah semua biaya yang digunakan dalam usahatani padi dan sayuran yang meliputi biaya tetap dan biaya variabel. Biaya tetap adalah biaya yang besarnya tidak mempengaruhi jumlah produksi, yang meliputi biaya sewa lahan, biaya pembelian peralatan seperti: tangki, sabit, cangkul dan lainnya. Untuk rata-rata biaya tetap pada usahatani padi yang dikeluarkan oleh petani menghabiskan biaya sebesar Rp. 977.027,74 LG/MT atau Rp. 244.256,93 LG/Bln atau Rp. 1.182.025,50 $\mathrm{Ha} / \mathrm{Bln}$. Sedangkan untuk rata-rata biaya tetap pada usahatani sayuran menghabiskan biaya sebesar Rp. 1.191.909,67 LG/MT atau Rp. 254.212,20 LG/Bln atau Rp. 1.235.840,44 $\mathrm{Ha} / \mathrm{Bln}$.
Biaya variabel adalah biaya yang besar kecilnya berpengaruh terhadap besar kecilnya produksi dan akan habis dalam satu kali proses produksi. Biaya variabel dalam usahatani padi dan sayuran ini meliputi biaya saprodi dan tenaga kerja meliputi: penyemprotan, pupuk, benih, dan lainya. Biaya variabel rata-rata yang dikeluarkan oleh petani padi yaitu sebesar $\mathrm{Rp} 2.398 .171,43$ LG/MT atau Rp. 599.542,86 LG/Bln atau Rp. 2.925.300,93 Ha/Bln. Sedangkan biaya variabel rata-rata yang dikeluarkan oleh petani sayuran yaitu sebesar Rp 4.664.300 LG/MT atau Rp. 1.007.390,45 LG/Bln atau Rp. 4.851.883,00 $\mathrm{Ha} / \mathrm{Bln}$. Rata-rata besarnya biaya total produksi usahatani padi adalah sebesar Rp. 3.375.199,17 LG/MT atau Rp. 843.799,79 LG/Bln atau Rp. 4.107.326,43 Ha/Bln dan Rata-rata besarnya biaya total produksi usahatani sayuran adalah sebesar Rp. 5.856.209,67 LG/MT atau Rp. 1.261.602,66 LG/Bln atau Rp. 6.087.723,43 Ha/Bln. Besarnya biaya yang dipergunakan pada usahatani padi dan sayuran dapat dilihat pada tabel berikut :

Tabel 3. Total Rata-rata Biaya Produksi Usahatani Padi dan Sayuran LG/MT di Desa Sumedang Sari.

\begin{tabular}{llrlc}
\hline No & Uraian Padi & Rp/LG/MT & Uraian Sayuran & Rp/LG/MT \\
\hline 1. & Biaya Tetap & $977.027,74$ & Biaya Tetap & $1.191 .909,67$ \\
2. & Biaya Variabel & $2.398 .171,43$ & Biaya Variabel & $4.664 .300,00$ \\
3. & Total Biaya & $3.375 .199,17$ & Total Biaya & $5.856 .209,67$ \\
\hline
\end{tabular}

Sumber : Hasil Olahan Data Primer, 2013.

Tabel 4. Total Rata-rata Biaya Produksi Usahatani Padi dan Sayuran LG/Bulan di Desa Sumedang Sari.

\begin{tabular}{llclr}
\hline No & Uraian Padi & Rp/LG/Bln & Uraian Sayuran & \multicolumn{1}{c}{ Rp/LG/Bln } \\
\hline 1. & Biaya Tetap & $244.256,93$ & Biaya Tetap & $254.212,20$ \\
2. & Biaya Variabel & $599.542,86$ & Biaya Variabel & $1.007 .390,45$ \\
3. & Total Biaya & $843.799,79$ & Total Biaya & $1.261 .602,66$ \\
\hline
\end{tabular}

Sumber : Hasil Olahan Data Primer, 2013.

Tabel 5. Total Rata-rata Biaya Produksi Usahatani Padi dan Sayuran Ha/Bulan di Desa Sumedang Sari.

\begin{tabular}{llrll}
\hline No & Uraian Padi & Rp Ha Bln & Uraian Sayuran & Rp/HaBln \\
\hline 1. & Biaya Tetap & $1.182 .025,50$ & Biaya Tetap & $1.235 .840,44$ \\
2. & Biaya Variabel & $2.925 .300,93$ & Biaya Variabel & $4.851 .883,00$ \\
3. & Total Biaya & $4.107 .326,43$ & Total Biaya & $6.087 .723,43$
\end{tabular}

Sumber : Hasil Olahan Data Primer, 2013. 


\section{Penerimaan, Pendapatan, $\mathrm{R} / \mathrm{C}$ Rasio, $\mathrm{B} / \mathrm{C}$ Rasio, BEP Harga dan BEP Produksi.}

Penerimaan merupakan perkalian antara total produk yang terjual dengan harga persatuan produk. Penerimaan usahatani padi dan sayuran semua berasal dari hasil produksi yang terjual. Lebih jelasnya mengenai jumlah produksi, harga dan penerimaan dari usahatani padi dan sayuran di Desa Sumedang Sari Kecamatan Buay Madang Timur Kabupaten OKU Timur dapat dilihat pada Tabel berikut :

Tabel 6. Total Rata-rata Produksi, Penerimaan dan Pendapatan Usahatani Padi dan Sayuran LG/MT di Desa Sumedang Sari.

\begin{tabular}{llrlr}
\hline No & Uraian Padi & \multicolumn{1}{c}{ LGMT } & Uraian Sayuran & \multicolumn{1}{c}{ LGMT } \\
\hline 1. & Produksi & $1.298 \mathrm{Kg}$ & Produksi & $7.456 \mathrm{Kg}$ \\
2. & Harga & Rp. 3.880 & Harga & Rp. 2.680 \\
3. & Penerimaan & Rp. 5.032 .800 & Penerimaan & Rp. 17.569 .500 \\
4. & Biaya Produksi & Rp. $3.375 .199,17$ & Biaya Produksi & Rp. $5.856 .209,67$ \\
5. & Pendapatan & Rp. $1.657 .600,83$ & Pendapatan & Rp. $11.713 .290,33$
\end{tabular}

Sumber : Hasil Olahan Data Primer, 2013.

Tabel 7. Total Rata-rata Produksi, Penerimaan dan Pendapatan Usahatani Padi dan Sayuran LG/Bulan di Desa Sumedang Sari.

\begin{tabular}{llrll}
\hline No & Uraian Padi & LG $B \ln$ & Uraian Sayuran & LG $B \ln$ \\
\hline 1. & Penerimaan & Rp. 1.258 .200 & Penerimaan & Rp. 3.817.984,09 \\
2. & Biaya Produksi & Rp. $843.799,79$ & Biaya Produksi & Rp. $1.261 .602,66$ \\
3. & Pendapatan & Rp. $414.400,21$ & Pendapatan & Rp. $2.556 .381,43$
\end{tabular}

Sumber : Hasil Olahan Data Primer, 2013.

Tabel 8. Total Rata-rata Produksi, Penerimaan dan Pendapatan Usahatani Padi dan Sayuran Ha/Bulan di Desa Sumedang Sari.

\begin{tabular}{llrlr}
\hline No & Uraian Padi & \multicolumn{1}{c}{$\mathrm{Ha} / \mathrm{Bln}$} & Uraian Sayuran & \multicolumn{1}{c}{$\mathrm{Ha} / \mathrm{Bln}$} \\
\hline 1. & Penerimaan & Rp. 6.150.926 & Penerimaan & Rp. $18.392 .939,81$ \\
2. & Biaya Produksi & Rp. $4.107 .326,43$ & Biaya Produksi & Rp. $6.087 .723,43$ \\
3. & Pendapatan & Rp. $2.043 .599,50$ & Pendapatan & Rp. $12.305 .216,38$
\end{tabular}

Sumber : Hasil Olahan Data Primer, 2013.

Pada tabel diatas menunjukan bahwa ratarata produksi padi per luas garapan menghasilkan $1.298 \mathrm{Kg}$ dengan harga Rp. 3.880 menghasilkan total penerimaan yaitu sebesar Rp. 5.032.800 LG/MT atau Rp. 1.258.200 LG/Bln atau Rp. 6.150.926 Ha/Bln.

Pendapatan atau keuntungan yang diperoleh dari usahatani padi merupakan selisih antara penerimaan dengan biaya total. Nilai pendapatan ini merupakan hasil bersih yang diperoleh selama proses produksi. Biaya produksi padi adalah sebesar Rp. 3.375.199,17 LG/MT atau Rp. 843.799,79 LG/Bln atau Rp. 4.107.326,43 Ha/Bln, selama masa tanam proses produksi akan diperoleh rata-rata pendapatan sebesar Rp. 1.657.600,83 LG/MT atau Rp. 414.400,21 LG/Bln atau Rp. 2.043.599,50 Ha/Bln.

Sedangkan untuk rata-rata produksi sayuran per luas garapan menghasilkan $7.456 \mathrm{Kg}$ dengan harga Rp. 2.680 menghasilkan total penerimaan yaitu sebesar Rp. 17.569.500 LG/MT atau Rp. 3.817.984,09 LG/Bln atau Rp. 18.392.939,77 $\mathrm{Ha} / \mathrm{Bln}$.

Pendapatan atau keuntungan yang diperoleh dari usahatani sayuran merupakan selisih antara penerimaan dengan biaya total. Nilai pendapatan ini merupakan hasil bersih yang diperoleh selama proses produksi. Biaya produksi sayuran adalah sebesar Rp. 5.856.209,67 LG/MT atau Rp. 1.261.602,66 LG/Bln atau Rp. 6.087.723,43 $\mathrm{Ha} / \mathrm{Bln}$ selama masa tanam proses produksi akan diperoleh rata-rata pendapatan sebesar Rp. 11.713.290,33 LG/MT atau Rp. 2.556.381,43 LG/Bln atau Rp. 12.305.216,38 Ha/Bln.

Tabel 9.Total Rata-rata R/C, B/C, dan BEP Usahatani Padi dan Sayuran di Desa Sumedang Sari.

\begin{tabular}{llrlr}
\hline No & Uraian Padi & \multicolumn{1}{c}{ LG/MT } & Uraian Sayuran & \multicolumn{1}{l}{ LG/MT } \\
\hline 1. & R/C & 1,50 & R/C & 3,05 \\
2. & B/C & 0,50 & B/C & 2,05 \\
3. & BEP Produksi & $484 \mathrm{Kg}$ & BEP Produksi & $657 \mathrm{Kg}$ \\
4. & BEP Harga & Rp. 2.600 & BEP Harga & Rp. 917
\end{tabular}

Sumber: Hasil Olahan Data Primer, 2013.

Tingkat keuntungan suatu analisis usaha dapat dinyatakan melalui $\mathrm{R} / \mathrm{C}$ rasio (return cost ratio) untuk mencari keuntungan penerimaan atau perbandingan antara penerimaan usaha dengan total biaya produksi. Dan $\mathrm{B} / \mathrm{C}$ rasio (benefit cost ratio) untuk mencari keuntungan pendapatan atau perbandingan pendapatan usaha dengan total biaya produksi.

Berdasarkan hasil perhitungan yang diperoleh dari usahatani padi, nilai $\mathrm{R} / \mathrm{C}$ rasio adalah sebesar 1,50. Nilai $\mathrm{R} / \mathrm{C}$ rasio sebesar 1,50 artinya bahwa setiap satu rupiah biaya yang dikeluarkan untuk usahatani padi akan menghasilkan penerimaan sebesar Rp 1,50. Nilai $\mathrm{R} / \mathrm{C}>1$, menunjukkan bahwa usahatani padi menguntungkan. Dan nilai B/C rasio sebesar 0,50 . Nilai $B / C$ rasio sebesar 0,50 artinya bahwa setiap satu rupiah biaya yang dikeluarkan untuk usahatani padi akan menghasilkan pendapatan sebesar $\mathrm{Rp} 0,50$. Nilai $\mathrm{R} / \mathrm{C}<1$, menunjukkan bahwa usahatani padi tidak menguntungkan. 
BEP produksi menggambarkan jumlah produksi minimal usahatani padi yang harus dihasilkan agar usahatani tidak mengalami kerugian. Berdasarkan hasil analisis data diketahui bahwa nilai dari BEP produksi padi adalah sebesar $484 \mathrm{Kg}$. Hal ini menunjukkan bahwa pada saat produksi padi mencapai $484 \mathrm{Kg}$ maka usahatani padi tidak untung dan tidak rugi. Berdasarkan hasil perhitungan diketahui bahwa nilai produksi padi yang dihasilkan oleh responden rata-rata sebesar $1.298 \mathrm{Kg}$ dan lebih besar dari nilai BEP produksi sehingga dapat dinyatakan usahatani padi layak secara financial.

Berdasarkan hasil analisis data maka diperoleh nilai dari BEP harga adalah Rp 2.600. Dan berdasarkan hasil penelitian menunjukkan bahwa harga jual Padi rata-rata adalah Rp $3.880 / \mathrm{Kg}$. Hal ini menunjukkan bahwa harga jual padi lebih tinggi dari pada nilai BEP harga yang berarti usahatani padi layak secara financial.

Berdasarkan hasil perhitungan yang diperoleh dari usahatani sayuran, nilai $\mathrm{R} / \mathrm{C}$ rasio adalah sebesar 3,05. Nilai R/C > 1, menunjukkan bahwa usahatani sayuran menguntungkan. Dan nilai $\mathrm{B} / \mathrm{C}$ rasio sebesar 2,05. Nilai $\mathrm{R} / \mathrm{C}>1$, menunjukkan bahwa usahatani sayuran menguntungkan.

BEP produksi menggambarkan jumlah produksi minimal usahatani sayuran yang harus dihasilkan agar usahatani tidak mengalami kerugian. Berdasarkan hasil analisis data diketahui bahwa nilai dari BEP produksi sayuran adalah sebesar 657. Hal ini menunjukkan bahwa pada saat produksi sayuran mencapai 657 maka usahatani sayuran tidak untung dan tidak rugi. Berdasarkan hasil perhitungan diketahui bahwa nilai produksi sayuran yang dihasilkan 7.456 lebih besar dari nilai BEP produksi sehingga dapat dinyatakan usahatani sayuran layak secara financial.

Berdasarkan hasil analisis data maka diperoleh nilai dari BEP harga adalah Rp 917. Dan berdasarkan hasil penelitian menunjukkan bahwa harga jual sayuran rata-rata adalah $\mathrm{Rp}$ 2.680. Hal ini menunjukkan bahwa harga jual sayuran lebih tinggi dari pada nilai BEP harga yang berarti usahatani sayuran layak secara financial.

\section{Uji-t}

Uji perbandingan pendapatan usahatani padi dengan sayuran dapat dilihat sebagai berikut:

$$
\mathrm{t}=\frac{\overline{\mathrm{x}}_{1}-\overline{\mathrm{X}}_{2}}{\sqrt{\frac{\left(n_{1}-1\right) \mathrm{s}_{1}^{n}+\left(n_{2}-1\right) \mathrm{s}_{2}^{n}}{n_{1}+n_{2}-2}\left(\frac{1}{n_{1}}+\frac{1}{n_{2}}\right)}}
$$

$$
\begin{aligned}
& \mathrm{t}=\frac{10.055 .689}{\sqrt{\frac{858,784.872 .960+71.881 .441 .494 .144}{18}(0,2)}}=11,83 \\
& \mathrm{t} \text { tabel }=2,101
\end{aligned}
$$

Artinya terjadi perbedaan yang signifikan antara usahatani padi dengan sayuran. Dengan tingkat signifikan $(\alpha) \quad 0,05$, yaitu diperoleh t_hitung 11,83 dan t_tabel 2,101, karena t_hitung $\geq$ t_tabel maka signifikan artinya terdapat perbedaan yang signifikan.

$$
\mathrm{t}=\frac{2.141 .981}{\sqrt{\frac{58.858 .898 .810+6.167 .408 .272 .021}{18}(0,2)}}=8,59
$$

Artinya terjadi perbedaan yang signifikan antara usahatani padi dengan sayuran. Dengan tingkat signifikan $(\alpha) \quad 0,05$, yaitu diperoleh t_hitung 8,59 dan t_tabel 2,101, karena t_hitung $\geq$ t_tabel maka signifikan artinya terdapat perbedaan yang signifikan.

$$
\mathrm{t}=\frac{10.261 .617{ }^{\mathrm{atau}}}{\sqrt{\frac{1.705 .076,429.819+60,757.586 .441 .204}{18}(0,2)}}=12,98
$$

Artinya terjadi perbedaan yang signifikan antara usahatani padi dengan sayuran. Dengan tingkat signifikan $(\alpha) \quad 0,05$, yaitu diperoleh t_hitung 12,98 dan t_tabel 2,101, karena t_hitung $\geq$ t_tabel maka signifikan artinya terdapat perbedaan yang signifikan.

\section{IV.KESIMPULAN DAN SARAN}

\section{A. Kesimpulan}

Berdasarnya hasil penelitian dan analisis yang telah dilakukan, maka dapat ditarik kesimpulan sebagai berikut:

1. Persepsi petani terhadap usahataninya (padi dan sayuran) dan dampak positif dari usahatani tersebut terhadap lahan sawah. Dari perhitungan persepsi petani padi diperoleh skor rata-rata 14,20 dan persentasi $56,80 \%$ yang masuk pada kriteria netral. Sedangkan untuk persepsi petani sayuran diperoleh skor rata-rata 17,50 dan persentasi $70,00 \%$ yang masuk pada kriteria setuju, yang artinya bahwa usahatani sayuran berdampak positif terhadap kesuburan lahan sawah. Dan dari hasil analisis usahatani padi diperoleh $\mathrm{R} / \mathrm{C}$ rasio sebesar 1,50, sedangkan hasil analisis usahatani sayuran diperoleh $\mathrm{R} / \mathrm{C}$ rasio sebesar 3,05 . Dari analisa persepsi dan nilai $\mathrm{R} / \mathrm{C}$ rasio 
usahatani sayuran lebih unggul dari pada usahatani padi.

2. Penerimaan usahatani padi sebesar Rp. 5.032.800 LG/MT atau Rp. 1.258.200 LG/Bln atau Rp. 6.150.926 Ha/Bln dan biaya yang dikeluarkan sebesar Rp. 3.375.199,17 LG/MT atau Rp. 843.799,79 LG/Bln atau Rp. 4.107.326,43 Ha/Bln, maka perolehan pendapatan usahatani padi sebesar Rp. 1.657.600,83 LG/MT atau Rp. 414.400,21 LG/Bln atau Rp. 2.043.599,50 Ha/Bln. Sedangkan untuk penerimaan usahatani sayuran sebesar Rp. 17.569.500 LG/MT atau Rp. 3.817.984,09 LG/Bln atau Rp. 18.392.939,77 Ha/Bln dan biaya yang dikeluarkan sebesar Rp. 5.856.209,67 LG/MT atau Rp. 1.261.602,66 LG/Bln atau Rp. 6.087.723,43 Ha/Bln, maka perolehan pendapatan usahatani sayuran sebesar $\mathrm{Rp}$. 11.713.290,33 LG/MT atau Rp. 2.556.381,43 LG/Bln atau Rp. 12.305.216,38 Ha/Bln. Dari perolehan pendapatan rata-rata, pendapatan usahatani sayuran lebih tinggi dibandingkan dengan pendapatan usahatani padi. Sedangkan selisih pendapatan yang dihasilkan sebesar Rp. 10.055.689,5 LG/MT atau Rp. 2.141.981,22 LG/Bln atau Rp. 10.261.616,88 $\mathrm{Ha} / \mathrm{Bln}$.

3. Dari hasil perhitungan menggunakan Uji-t antara usahatani padi dengan sayuran. Dengan tingkat signifikan $(\alpha) \quad 0,05$, yaitu diperoleh t_hitung 11,83 LG/MT, 8,59 LG/Bln, 12,98 Ha/Bln dan t_tabel 2,101, karena t_hitung $\geq$ t_tabel maka signifikan artinya terdapat perbedaan yang signifikan.

\section{B.Saran}

1. Dalam berusahatani pada lahan sawah hendaknya untuk mengatur pola tanam (pergantian jenis tanaman) agar kesuburan pada lahan sawah tetap bagus dan dapat memutus mata rantai perkembangan hama dan penyakit pada lahan sawah.

2. Dalam berusahatani hendaknya petani tidak monoton dengan satu varian, harus ada usahatani lain supaya ketika yang satu gagal masih ada penghasilan usahatani lainnya.

\section{DAFTAR PUSTAKA}

Anonim. 2009. Tanaman Padi. Departemen Pertanian. Jawa Barat.
Anonim. 2010. Laporan Tahunan Tanaman. Dinas Pertanian Tanaman Pangan dan Hortikultura Kabupaten OKU Timur.

Anonim. 2011. Pertumbuhan Penduduk Indonesia. BPS Jakarta.

Azzoino. 2003. Ilmu Usahatani. Universitas Terbuka. Jakarta.

Daniel, Mosher. 2002. Metode Penelitian Sosial Ekonomi di Lengkapi Beberapa Alat Dan Analisa dan Penuntut Pengguna. Jurnal Ilmi-ilmu Pertanian. Vol. 5, No 1, pp. 1-21.

Endah. 2003. Penggunaan Pestisida. PT Agro Media. Jakarta.

Glaszman. 1987. Botani Padi. Pustaka Sinar Harapan. Jakarta.

Hernanto, F. 2005. Ilmu Usaha Tani I. Penebar Swadaya. Jakarta.

Ibrahim. 2003. Study Kelayakan Bisnis. PT Rineka Cipta. Jakarta.

Joesi. 2008. Penanganan Pasca Panen. Sinar Tani. Yogyakarta.

Kartasoepatra, A.G. 2006. Pengantar Ekonomi Produksi. Bina Aksana. Jakarta.

Koutsoyiannis, A. 2004. Modern Microeconomics, Second Edition, Macmillan Education LTD Houndmills, Basingstoke, Hamspire RG21 2XS. London.

Mubyarto. 2007. Pengantar Ekonomi Pertanian. LP3ES. Jakarta.

Novizan. 2003. Petunjuk Pemakaian Air. PT Agro Media. Jakarta.

Nurhayati. 2001. Ekonomi Pertanian. Universitas Terbuka. Jakarta.

Purnawati. 2007. Analisis Usaha Tani. Fakultas Pertanian Universitas Gajah Mada. Yogyakarta.

Saragih, B. 2001. Kumpulan Pemikiran Agribisnis Paradigma Baru Pembangunan Ekonomi Berbasis Pertanian. Pustaka Wirausaha Muda. Bogor. 
Setiadi. 2007. Bertanam sayuran. Penebar swadaya. Jakarta.

Setyono. 2006. Padi Sawah Varietas Unggul. Rineka Cipta. Jakarta.

Shim, Jae K, Ph. D. And Joel G. Siegel, Ph. D., CPA. 1992. Modern Cost Management \& Analysis, Barron's Educational Series, Inc. 250 Wireless Boulvard Hauppaunge, New York 11788.

Shinji. 2012. Usahatani. http://Shinjiblack.blogspot.co.id/2012/06/usahatani.htm 1. Diakses pada tanggal 06 Mei 2013.

Sjarkowi, F. 2010. Manajemen Agribisnis. CV Baldad Grafiti Press. Palembang.

Sjarkowi, F danSufri, M. 2004. Manajemen Agribisnis. CV Baldad Grafiti Press. Palembang.

Soekartawi. 2004. Prinsip Dasar Ekonomi Pertanian. Raja Grafindo Persada. Jakarta.

Soekartawi. 2005. Teori Ekonomi Produksi. CV Rajawali. Jakarta.

Sudarsono. 2004. Pengantar Ekonomi Micro. LP3ES. Jakarta.

Sugiyono. 2012. Metode Penelitian Bisnis. Alfabeta. Bandung.
Sunarjono, H. 2005. Bertanam 30 Jenis Sayur. Jakarta; PT Penebar Swadaya.

Suratiyah, Ken. 2006.Ilmu Usahatani. Cetakan I. Penerbit Penebar Swadaya. Jakarta.

Tambunan, T. 2010. Pembangunan Pertanian dan Ketahanan Pangan. Universitas Indonesia-press. Jakarta.

Toher, K. 2006. Seuntai Pengetahuan Tentang Usahatani Indonesia. PT Bina Aksara. Jakarta.

Umar, H. 2002. Riset Pemasaran dan Perilaku Konsumen. PT. Gramedia Pustaka Utama. Jakarta. 